\title{
Discordant serum lipid parameters
}

\author{
Ozge Kurmus ${ }^{*}$, Turgay Aslan, Murat Eren, Kursat Akbuga
}

\section{Dear Editor,}

We read with interest the paper by Fonseca et al. entitled "Apolipoprotein B and non-high-density lipoprotein cholesterol reveal a high atherogenicity in individuals with type 2 diabetes and controlled low-density lipoprotein-cholesterol" [1]. The authors state that $22 \%$ of the diabetic patients with target low-density lipoprotein cholesterol (LDL-C) level had non-high-density lipoprotein cholesterol (non-HDL-C) level above the target level. Target levels were defined according to the European Society of Cardiology/European Atherosclerosis Society 2016 Guideline for the Management of Dyslipidemia [2].

We previously demonstrated that in 574 consecutive patients who underwent coronary angiography, $15 \%$ of them had discordance between LDL-C and non-HDL-C levels [3]; $30 \%$ of our study group had type 2 diabetes mellitus (T2DM). In our study, patients with a high difference between non-HDL-C and LDL-C levels were more commonly females, had T2DM and high triglyceride levels [3]. Also, they less commonly received statin therapy [3]. Both the current study [1] and our study [3] measured fasting blood lipids. Measuring apolipoprotein B (Apo B) and oxidized LDL-C level is one of the advantages of the Fonseca et al. study [1]. The authors reported that in addition to non-HDL-C, Apo B and oxidized LDL-C levels were above the recommended range in 25 and $44 \%$ of the patients with controlled LDL-C levels, respectively. NonHDL-C, Apo B and oxidized LDL-C are all potential atherogenic lipid particles $[4,5]$. The findings of Fonseca et al. [1] add significant information to previously published data. Comparing the characteristics of patients with non-HDL-C, Apo B and oxidized LDL-C below target with non-HDL-C, Apo B and oxidized LDL-C above target in groups within and above target LDL-C levels separately would be useful for better understanding which patient might have discordant lipid parameters.

Although the size of the study populations and the cut-off values for LDL-C and non-HDL-C to classify patients differ between the current study [1] and our study [3], we both pointed out that sizeable proportion of patients may have low LDL-C and high non-HDL-C levels; T2DM seems to be a risk factor for this pattern. In our study [3], patients with low LDL-C and high non-HDLC had higher levels of triglycerides than the other patients and high triglyceride levels have been related to discordance of LDL-C and non-HDL-C in previous studies [6, 7]. In the current study [1], there was no significant difference between patients with LDL-C levels within and above target regarding triglyceride levels.

Further studies should be designed to understand the demographic, clinical and laboratory characteristics of patients with discordant lipid parameters. Moreover, the prognosis of cardiovascular disease should be further investigated in follow-up studies in these patients. Despite the low levels of LDL-C, some patients still experience cardiovascular events and patients with low levels of LDL$\mathrm{C}$ but with higher levels of other atherogenic lipid particles may need further evaluation, more aggressive management and close follow-up.

\section{Reply to "Discordant serum lipid parameters"}

Liliana Fonseca, Silvia Paredes, Isabel Palma

We would like to thank for the kind words of appreciation for our study. Despite extraordinary advances in the atherosclerotic cardiovascular disease treatment field, it remains the leading cause of death worldwide.

\footnotetext{
* Correspondence: ozge_kurmus@yahoo.com

Department of Cardiology, Faculty of Medicine, Ufuk University, Mevlana Bulvari (Konya yolu), No: 86-88, Balgat, Ankara, Turkey
}

Reducing low-density lipoprotein-cholesterol (LDL-c) is the foundation of atherosclerotic risk reduction. In fact, an LDL-c reduction, namely with statins, has served as the foundation for primary and secondary prevention for decades and has led to significant improvement in cardiovascular outcomes [8]. However, a significant 
residual risk of cardiovascular events, despite optimal risk factor management, seems to remain in many patients. Beyond traditional risk factors, other factors have emerged, including inflammatory, prothrombotic, and metabolic pathways. These factors contribute to recurrent events and are often unrecognized and not addressed in clinical practice.

Inflammation has been postulated to play an important role in atherosclerosis development [9]. Besides LDL-c lowering, statins are known to have multiple pleiotropic effects and several trials demonstrated consistent anti-inflammatory effects [10], that may benefit the overall atherosclerosis process. Several lines of evidence support the concept that oxidized-LDL-c, a marker of inflammation, may be a key factor in atherosclerosis [9]. Oxidized-LDL-c, through inflammation, can contribute to enhance residual risk. Although not frequently measured in clinical practice, oxidized LDL-c can be of value, by identifying patients that may need further evaluation and more aggressive management. As evidenced by our study, $44 \%$ of the patients with type 2 diabetes and LDL-c within target, still presented high levels of oxidized-LDL-c [11]. Apolipoprotein B (ApoB) evaluation has been recognized in the 2019 European Society of Cardiology / European Atherosclerosis Society Guidelines for the management of dyslipidemias has a preferred lipoprotein to be measured in patients with type 2 diabetes mellitus or high triglyceride levels [8]. ApoB provides an accurate estimate of the total concentration of atherogenic particles ad it has been demonstrated that, in these patients, a discordance between measured LDL-c and ApoB levels can occur, underestimating LDL-c levels [8]. Our study, was performed previous to the publication of these guidelines, and it confirms the association between LDL-c within target and ApoB levels above target [11]. The findings of Kurmus et al., where 15\% of patients with high cardiovascular risk had discordance between LDL-c and non-high density lipoprotein cholesterol (non-HDL-c) [3], highlight the importance of addressing residual risk. Naturally, further studies are needed in order to evaluate the effect of targeting these factors, together with LDL-c reduction, in the number of cardiovascular events.

Finally, the knowledge of the population which may further benefit with the targeting of the residual risk factors is highly needed. Kurmus et al. identified female gender, type 2 diabetes mellitus and high triglyceride levels as characteristics of patients with divergent LDL-c and non-HDL-c [3], whereas our group has previously identified the presence of metabolic syndrome [12], as well, as type 2 diabetes [11]. We expect, as years go by, that science unravels the characteristics of patients with discordant lipid parameters, so that physicians can promote a patient tailored approach and further reduce cardiovascular events.

\section{Abbreviations \\ Apo B: Apolipoprotein B; LDL-C: low-density lipoprotein cholesterol; Non- HDL-C: non-high-density lipoprotein cholesterol}

\section{Acknowledgements}

Not applicable.

\section{Authors' contributions}

OK: major contributor in writing the letter. OK, TA, ME, KA, read and interpreted the article which was previously published in Lipids in Health and Disease journal. All the authors read and approved the final version of the letter.

\section{Funding \\ None.}

Availability of data and materials

Not applicable.

Ethics approval and consent to participate

Not applicable (This is a "letter to the editor").

\section{Consent for publication}

Not applicable.

\section{Competing interests}

None.

Received: 3 November 2020 Accepted: 7 February 2021

Published online: 11 February 2021

\section{References}

1. Fonseca L, Paredes S, Ramos H, Oliveira JC, Palma I. Apolipoprotein $B$ and non-high-density lipoprotein cholesterol reveal a high atherogenicity in individuals with type 2 diabetes and controlled low-density lipoproteincholesterol. Lipids Health Dis. 2020;19:127.

2. Catapano AL, Graham I, De Backer G, Wiklund O, Chapman MJ, Drexel H, et al. 2016 ESC/EAS guidelines for the management of dyslipidaemias. Eur Heart J. 2016:37:2999-3058.

3. Kurmus O, Erkan AF, Ekici B, Aslan T, Eren M. Discordance of lowdensity lipoprotein Cholestrol and non-high-density lipoprotein Cholestrol and coronary artery disease severity. Arq Bras Cardiol. 2020; 114:469-75.

4. Pischon T, Girman CJ, Sacks FM, Rifai N, Stampfer MJ, Rimm EB. Non-highdensity lipoprotein cholesterol and apolipoprotein B in the prediction of coronary heart disease in men. Circulation. 2005;112: 3375-83.

5. Kattoor AJ, Kanuri SH, Mehta JL. Role of ox-LDL and LOX-1 in Atherogenesis. Curr Med Chem. 2019;26:1693-700.

6. Kuwabara K, Harada S, Sugiyama D, Kurihara A, Kubota Y, Higashiyama A, et al. Relationship between non-high-density lipoprotein cholesterol and lowdensity lipoprotein cholesterol in the general population. J Atheroscler Thromb. 2016;23:477-90.

7. Mora S, Buring JE, Ridker PM. Discordance of low-density lipoprotein (LDL) cholesterol with alternative LDL-related measures and future coronary events. Circulation. 2014;129:553-61.

8. Mach F, Baigent C, Catapano AL, Koskinas KC, Casula M, Badimon L, et al. 2019 ESC/EAS guidelines for the management of dyslipidaemias: lipid modification to reduce cardiovascular risk. Eur Heart J. 2020; 41(1):111-88.

9. Hulthe J, Fagerberg B. Circulating oxidized LDL is associated with subclinical atherosclerosis development and inflammatory cytokines (AIR study). Arterioscler Thromb Vasc Biol. 2002;22(7):1162-7

10. Dhindsa DS, Sandesara PB, Shapiro MD, Wong ND. The evolving understanding and approach to residual cardiovascular risk management. Front Cardiovasc Med. 2020;7:88. 
11. Fonseca L, Paredes S, Ramos H, Oliveira JC, Palma I. Apolipoprotein B and non-high-density lipoprotein cholesterol reveal a high atherogenicity in individuals with type 2 diabetes and controlled low-density lipoproteincholesterol. Lipids Health Dis. 2020;19(1):127.

12. Paredes S, Fonseca L, Ribeiro L, Ramos H, Oliveira JC, Palma I. Novel and traditional lipid profiles in metabolic syndrome reveal a high atherogenicity. Sci Rep. 2019;9(1):11792.

\section{Publisher's Note}

Springer Nature remains neutral with regard to jurisdictional claims in published maps and institutional affiliations.

Ready to submit your research? Choose BMC and benefit from:

- fast, convenient online submission

- thorough peer review by experienced researchers in your field

- rapid publication on acceptance

- support for research data, including large and complex data types

- gold Open Access which fosters wider collaboration and increased citations

- maximum visibility for your research: over $100 \mathrm{M}$ website views per year

At $\mathrm{BMC}$, research is always in progress.

Learn more biomedcentral.com/submissions 